\title{
Ankle Brachial Index As A Monitor of Diabetes Type 2 Microvascular Complications
}

\author{
JEHAN SAEED, M.D.*; AMIRA AHMED MAHMOUD, M.D.*; ABEER A. SAEED, M.D.** and \\ NAGLAA A. AHMED, M.D.** \\ The Departments of Internal Medicine* and Physiology**, Faculty of Medicine, Zagazig University
}

\begin{abstract}
Background: Peripheral Artery Disease (PAD) has been linked with diabetic microvascular complications. However, many patients do not show typical symptoms. Ankle-Brachial Index $(\mathrm{ABI})$ is reported to be a simple and useful method to estimate cardiovascular risks.

Aim of Study: To determine whether Ankle-brachial index could be a useful monitor of development of micro vascular complications in type 2 diabetes.

Patients and Methods: A cross sectional study included 93 patients, classified into two groups: Group I (control group) consistsed of 10 healthy individuals. Group II (patient group): Consisted of 83 diabetes type 2 patients diagnosed according to ADA criteria; who were further subdivided according to presence or absence of microvascular complications into two groups: Group IIA: 10 diabetics without microangiopathy and Group IIB: 73 Diabetics with microangiopathy. All the study members were subjected to clinical evaluation, fundus examination, serial measurement of blood pressure, fasting \& postprandial blood glucose, HbA1c, serum creatinine, urinary albumin and ABI.
\end{abstract}

Results: Our results showed significant higher BMI and lower ABI in diabetic groups compared to control $(p<0.05)$; where fasting blood glucose, postbrandial blood glucose, $\mathrm{HbA} 1 \mathrm{c}$ and serum creatinine were significantly elevated diabetic groups compared to control $(p<0.05)$. A significant negative correlations $(p<0.000)$ between BMI, HbAlc and duration of DM with ABI. The incidance of microvacular complications (retinopathy, nephropathy \& neuropathy) was significantly higher $(p 0.00)$ in complicated diabetic group (Group IIB) compared to control and IIA groups. The average ABI was significantly lower $(p<0.05)$ among complicated diabetic group (Group IIB) regarding retinopathy (proliferative $\&$ non proliferative), nephropathy (micro \& macroalbuminria) and neuropathy (mild, moderate $\&$ sever).

Conclusion: Low ABI is common in patients with T2D. The ABI is a simple, reproducible, and cost-effective screening test for diagnosing microvascular complications in diabetes type 2 patients. ABI screening should be performed in diabetic population for early evaluate of microvascular complications.

Correspondence to: Dr. Abeer A. Saeed, E-Mail: muhoosh@gmail.com
Key Words: Ankle brachial index (ABI) - Type 2 diabetes (T2D) - Peripheral arterial disease (PAD) Microvascular complications.

\section{Introduction}

DIABETES Mellitus (DM) has become a worldwide epidemic. Globally, 422 million adults were estimated to have diabetes with a total prevalence of $8.5 \%$ in 2014 [1]. Up to $29 \%$ of population over age 70 in USA are affected by Peripheral Artery Disease (PAD), according to the population sampled [2]. Although PAD classic symptom is intermittent claudication, yet most patients are not presented with intermittent claudication; they complain of atypical lower extremity symptoms or even no symptoms [3]. Detection of PAD is important since it is common and possesses serious complications (amputation, impaired functional capacity, poor quality of life, and depression), and effective treatments are available [4].

Not only, the non-invasive vascular assessment is crucial for the detection of Peripheral Arterial Disease (PAD), but also early diagnosis is essential to evaluate cardiovascular risk factors that could be managed and to avoid more serious complications [5]. Calculating a patient's Ankle-brachial Pressure Index (ABI) is a non-invasive, simple and low-cost method for detection of peripheral artery disease in the lower limbs [6]. ABI is considered to be a valuable indicator of the severity of atherosclerosis in lower limbs and was related to microvascular dysfunction of the largest tissue in the body-skeletal muscles-which is insulinsensitive and crucial for glucose utilization and metabolism [7]. The prevalence of PAD ranges between $9.5 \%$ and $13.6 \%$ in patients with $\mathrm{T} 2 \mathrm{D}$, compared with a prevalence of $4 \%$ in the general population [8]. 
This study was conducted to evaluate the role of $\mathrm{ABI}$ as a monitor for the development of micro vascular complications of type 2 diabetes.

\section{Patients and Methods}

This study was conducted in the Department of Internal Medicine, Endocrinology Unit, Zagazig University Hospitals in the period from 1/1/2017 to $1 / 12 / 2017$. It included total number 93 patient, they were classified according to presence or absence of Diabetes Mellitus into two main groups: Group I (control group): It included 10 healthy individuals: 7 males and 3 females. Their healthy state proved by history and clinical examination. Group II (patient group): This group includes 83 patient diagnosed as Type 2 diabetes according to ADA criteria. There are 61 males and 22 females. They were further subdivided according to presence or absence of microvascular complications into two groups: Group IIA: 10 diabetics without microangiopathy 7 males and 3 females. Group IIB: 73 diabetics with microangiopathy 54 males and 19 females.

Inclusion criteria: Type 2DM, age above 18 years.

Exclusion criteria: Type 1 diabetic patient, chronic kidney disease, presence of sepsis or any source of infection and spinal stenosis.

All patients of the study were subjected to the following: Full history taking and clinical examination: Full neurological examination to detect diabetic neuropathy, fundus examination to detect diabetic retinopathy and serial measurement of blood pressure. Fasting blood glucose, postprandial blood glucose, $\mathrm{HbA1c}$, serum creatinine and urinary albumin were done. Fundus examination and Doppler on both limbs was performed.

Measurement of ABI: The patient was placed in a supine position for 5 minutes, measurement of systolic blood pressure is in both arms was done, the higher value is used as the denominator of the $\mathrm{ABI}$, measurement of systolic blood pressure in the dorsalis pedis and posterior tibial arteries was performed by placing the cuff just above the ankle, the higher value is the numerator of the $\mathrm{ABI}$ in each limb [9]

The diagnostic criteria for PAD based on the ABI are interpreted as follows: Normal if 0.911.30 , mild obstruction if $0.70-0.90$, moderate obstruction if 0.40-0.69, severe obstruction if $<0.40$, poorly compressible if $>1.30$, an ABI value $>1.3$ poorly compressible arteries [9].
Assessment of diabetic retinopathy: All diabetic patients with microangiopathies were consulted by ophthalmologist for detection and grading of retinopathy by fundus examination. If there is retinopathy it was classified into: Non proliferative retinopathy and Proliferative retinopathy according to $[10]$

Assessment of diabetic nephropathy: All diabetic patients were screened for diabetic nephropathy by measurement of Urinary Albumin. We regarded albumin levels of $<30 \mathrm{mg} /$ day as normoalbuminuria, $30-300 \mathrm{mg} /$ day as microalbuminuria, and $>300$ $\mathrm{mg} /$ day as macroalbuminuria [11]

Assessment of peripheral sensory neuropathy: All diabetic patients were exposed to full neurological examination to detect diabetic neuropathy. The bedside Neuropathy Disability Score (NDS) was derived from examining vibration perception (using a 128-Hz tuning fork), pin-prick and temperature perceptions in the big toe, and the presence or absence of ankle reflexes. The sensory modalities were scored as either present $(0)$ or reduced or absent (1) for each leg; ankle reflexes were scored as normal (0), present with reinforcement (1), or absent (2) for each leg. The total maximal abnormal score was 10 . A score above 2 was defined as clinical DPN. A physician who was specially trained by a senior diabetologist performed the neurological examination. Accordingly diabetic neuropathy was classified into: Mild (3-5), moderate (6-8) and sever (9-10) [12] .

Informed consent was obtained from all subjects prior to inclusion in the study. Patients were informed about their results and followed up by their physicians. The study was approved by the Local Ethical Committee.

\section{Statistical analysis:}

Data were entered, checked and analyzed using SPSS program package Version 25 for windows. $p<0.05$ was considered significant.

\section{Results}

The clinical characteristics of the studied groups showed non-significant difference in age among all groups $(p>0.05)$, while BMI was significantly higher in patients compared to control and Group IIB was significantly higher than Group IIA ( $p$ $<0.05)$. ABI significantly lower in patients compared to control and Group IIB was significantly lower than Group IIA $(p<0.05)$ Table $(1)$. 
Table (1): Clinical characteristics of all studied groups.

\begin{tabular}{llll}
\hline & Group I & Group IIA & Group IIB \\
\hline Age $($ years $)$ & $52.6 \pm 13.4$ & $53.3 \pm 14.9$ & $56.6 \pm 17.4$ \\
BMI $\left(\mathrm{kgm} / \mathrm{m}^{2}\right)$ & $24.2 \pm 2.9$ & $23.9 \pm 2.3^{*}$ & $26.5 \pm 2.1 * \#$ \\
Ankle Brachial Index (ABI) & $1.08 \pm 0.1$ & $1.1 \pm 0.9^{*}$ & $0.8 \pm 0.19 * \#$ \\
\hline$*:(p<0.05)$ versus control & & & \\
$\#:(p<0.05)$ versus Group IIB. & & & \\
\end{tabular}

Fasting blood glucose, post prandial blood glucose and HbA lc were significantly higher in Group IIA and Group IIB $(p<0.05)$ compared to the control group. Serum creatinine was significantly $(p<0.05)$ higher in Group IIB compared to control group. Post prandial blood glucose and serum creatinine were significantly higher in Group IIB compared to Group IIA (Table 2).

Table (2): Laboratory characteristics of different groups of study.

\begin{tabular}{llll}
\hline & Group I & Group IIA & Group IIB \\
\hline $\begin{array}{l}\text { - Fasting blood glucose } \\
(\mathrm{mg} / \mathrm{dL})\end{array}$ & $92.0 \pm 30.47$ & $167.0 \pm 13.3^{*}$ & $171.0 \pm 39.8^{*}$ \\
- Post prandial blood & $111.0 \pm 10$ & $201 \pm 16.6^{*}$ & $267.5 \pm 40.7^{* \#}$ \\
$\quad$ glucose (mg/dL) & & & \\
- HBA1c & $5.4 \pm 0.9$ & $7.9 \pm 0.9^{*}$ & $9.9 \pm 1.5^{*}$ \\
- Serum creatinine (mg/dL) & $0.55 \pm 0.1$ & $0.8 \pm 0.2$ & $1.45 \pm 0.5^{*} \#$ \\
\hline *: $(p<0.05)$ versus control & & & \\
$\#:(p<0.05)$ versus Group IIB. & &
\end{tabular}

ABI shows a significant negative correlation $(p<0.000)$ with BMI, HbA1c and duration of DM (Table 3).

Table (3): Correlation between ABI and HBA1, BMI \& duration of DM.

\begin{tabular}{lcc}
\hline \multirow{2}{*}{ Variables } & \multicolumn{2}{c}{ Ankle Brachial Index } \\
\cline { 2 - 3 } & Correlation & $p$-value \\
\hline HBA1 c & $-0.459^{*}$ & 0.00 \\
BMI & $-0.503^{*}$ & 0.00 \\
Duration of diabetes & $-0.495^{*}$ & 0.00 \\
\hline
\end{tabular}

*: Significant $(p<0.05)$.

Control and Group IIA showed significant lower $(p<0.000)$ incidence of retinopathy compared to Group IIB which also, showed significantly higher incidence of non-proliferative and proliferative retinopathy (Table 4).

Table (4): Distribution of retinopathy in different studied groups.

\begin{tabular}{|c|c|c|c|c|c|c|c|c|}
\hline & \multicolumn{2}{|c|}{ Group I } & \multicolumn{4}{|c|}{ Group IIa Group IIB } & \multirow{2}{*}{$x^{2}$} & \multirow{2}{*}{$\begin{array}{c}p- \\
\text { value }\end{array}$} \\
\hline & No. & $\% \mathrm{I}$ & No. & $\%$ & No. & $\%$ & & \\
\hline \multicolumn{9}{|l|}{ Retinopathy: } \\
\hline Absent & 10 & 100 & 10 & 100 & 36 & 49.3 & 16.8 & $0.00 *$ \\
\hline Non proliferative & 0 & 0 & 0 & 0 & 34 & 46.6 & & \\
\hline Proliferative & 0 & 0 & 0 & 0 & 3 & 4.1 & & \\
\hline
\end{tabular}

Control and Group IIA showed significant lower $(p<0.000)$ incidence of nephropathy compared to Group IIB which also, showed significantly higher incidence of microalbumenuria and macroalbumenuria (Table 5).

Table (5): Distribution of nephropathy different studied groups.

\begin{tabular}{|c|c|c|c|c|c|c|c|}
\hline & \multicolumn{2}{|c|}{ Group I } & \multicolumn{4}{|c|}{ Group IIa Group IIB } & \multirow{2}{*}{$x^{2}$} \\
\hline & No. & $\% 1$ & No. & & No. & $\%$ & \\
\hline \multicolumn{8}{|l|}{ Nephropathy: } \\
\hline Absent & 10 & 100 & 10 & 100 & 19 & 26 & $35.20 .00 *$ \\
\hline Microalbumenuria & 0 & 0 & 0 & 0 & 34 & 36.6 & \\
\hline Macroalbumenuria & 0 & 0 & 0 & 0 & 20 & 21.5 & \\
\hline
\end{tabular}

*: Significant $(p<0.05)$

Control and Group IIA showed significant lower $(p<0.000)$ incidence of neuropathy compared to Group IIB which also, showed significantly higher incidence of mild, moderate and sever neuropathy (Table 6).

Table (6): Distribution of neuropathy in different studied groups.

\begin{tabular}{|c|c|c|c|c|c|c|c|c|}
\hline & \multicolumn{2}{|c|}{ Group I } & \multicolumn{4}{|c|}{ Group IIa Group IIB } & \multirow{2}{*}{$x^{2}$} & \multirow{2}{*}{$\begin{array}{c}p- \\
\text { value }\end{array}$} \\
\hline & No. & $\%$ & No. & $\%$ & No. & $\%$ & & \\
\hline \multicolumn{9}{|l|}{ Neuropathy: } \\
\hline Absent & 10 & 100 & 10 & 100 & 15 & 20.5 & 42.2 & $0.00 *$ \\
\hline Mild & 0 & 0 & 0 & 0 & 24 & 32.9 & & \\
\hline Moderate & 0 & 0 & 0 & 0 & 23 & 31.5 & & \\
\hline Severe & 0 & 0 & 0 & 0 & 11 & 15.1 & & \\
\hline
\end{tabular}

*: Significant $(p<0.05)$.

The average Ankle-Brachial Index (ABI) was significantly lower $(p<0.05)$ in non-proliferative retinopathy compared to the group with absent retinopathy; it was significantly lower $(p<0.05)$ in the groups of microalbumenuria and macroalbumenuria in relation to the group of absent nephropathy. ABI was significantly lower $(p<0.05)$ in moderate and sever neuropathy groups when compared to mild or without neuropathy (Table 7).

Table (7): Average Ankle-Brachial Index (ABI) among the groups of diabetic retinopathy, nephropathy and neuropathy.

\begin{tabular}{|c|c|c|c|c|}
\hline & \multicolumn{4}{|c|}{ Retinopathy } \\
\hline & Absent & Non- $\mathrm{p}$ & liferative & Proliferative \\
\hline \multirow[t]{3}{*}{$\mathrm{ABI}$} & $0.97 \pm 0.21$ & & $\pm 0.1^{*}$ & $0.8 \pm 0.2$ \\
\hline & \multicolumn{4}{|c|}{ Nephropathy } \\
\hline & Absent & Microalbu & enuria & Macroalbumenuria \\
\hline \multirow[t]{3}{*}{ ABI } & $1.01 \pm 0.17$ & $0.83 \pm($ & & $0.76 \pm 0.08^{*}$ \\
\hline & \multicolumn{4}{|c|}{ Neuropathy } \\
\hline & Absent & Mild & Moderate & Sever \\
\hline ABI & $1.00 \pm 0.17$ & $0.93 \pm 0.23$ & $0.76 \pm 0.13^{*}$ & $0.78 \pm 0.13 * \#$ \\
\hline
\end{tabular}




\section{Discussion}

Diabetes was reported to be the main cause of blindness, End-Stage Renal Disease (ESRD) and limb amputation; development of microvascular complications namely retinopathy, nephropathy and neuropathy is linked to several environmental risk factors, including duration of diabetes, degree of hyperglycemia and dyslipidemia [13] .

Peripheral Artery Disease (PAD) is largely associated with diabetes mellitus. Many epidemiological studies have shown a 2-to 4-fold increased risk for developing PAD, with ankle- brachial index $<0.90[14,15]$. Patients with diabetes mellitus developed PAD in a higher percentage than non-diabetic patients [16].

The present study showed significantly higher $\mathrm{BMI}$ in diabetic patients compared to control group; in agreement with previous studies that reported an increased prevalence of type 2 diabetes due to obesity. These studies showed positive association between obesity and the risk of diabetes development among population; moreover, a doubled probability of having diabetes in obese than lean persons was found [17-19]

The present study revealed significant lower BAI in diabetic groups compared to control in accordance to previous studies $[\mathbf{2 0 , 2 1 ]}$ that reported low $\mathrm{ABI}$ in diabetics and relate it to increased risk of PAD. ABI was considered to be a good marker of atherosclerosis, morbidity and mortality for cardiovascular diseases in diabetic patients [22] The underlying pathophysiology may be endothelial dysfunction, inflammation and insulin resistance representing common ground for development of atherosclerosis [23]. Biochemical investigation of the current study revealed significant elevation of fasting, postprandial blood glucose, glycated hemoglobin and serum Creatinine in diabetic groups compared to control one. These findings were reported previously [24], elevated levels of $\mathrm{HbA1c}$ were linked to the development of microvascular events in type 2 diabetic patients [25], also impairment of renal functions has been linked to atherosclerosis [26]

Moreover, negative correlation between ABI and HBA1c, BMI and duration of diabetes as previously reported [27].

Atherogenesis may be potentiated by hyperglycemia which leads to inhibition of arterial endothelial Nitric Oxide (NO) production, induction of vascular smooth muscle cell proliferation, stimu- lation of PAI-1 production, and accumulation of advanced glycation end products [28].

The results of the current study showed higher incidence of diabetic retinopathy in diabetic group with complication than control non-complicated groups and it was linked to lower ABI. This was found in preceding studies, who noted that neovascularization which is the main finding in proliferative diabetic retinopathy and angiogenesis has frequently been related to advanced atherosclerotic $[29,30]$

Previous studies evaluated the association of low ABI and proliferative retinopathy, and they explained that atherosclerosis and diabetic retinopathy share common risk factors for their development [31] known as "common mechanism" for the development of macro-and microangiopathy in diabetes type 2, which includes obesity, insulinresistance and hypertension [32] .

The present study showed higher incidence of macro-and microalbuminuria in diabetic group with complication when compared to control noncomplicated groups and was associated with lower ABI. This was also reported in previously. These studies also regarded $\mathrm{ABI}$ as a reliable, noninvasive marker for detecting not only the peripheral and cardiovascular complications, but also the early stages of diabetic nephropathy $[33,34]$. In addition, albuminuria may cause increased cardiovascular complications directly, or could be a marker of enhanced platelet aggregation, endothelial invasion with atherogenic lipoprotein particles, or autonomic neuropathy [35].

The present study also, showed increased incidence of neuropathy in diabetic complicated group compared to control and non-complicated groups with higher association of neuropathy with low ABI. In line with previous studies that pointed to a higher incidence or deterioration of peripheral neuropathy in diabetics with low ABI [36] . Early recognition and suitable management of neuropathy in diabetic patients are mandatory [37]

\section{Conclusion:}

Low ABI is common in patients with T2D. The $\mathrm{ABI}$ is a simple, reproducible, and cost-effective screening test for diagnosing microvascular complications in diabetes type 2 patients. ABI screening should be performed in diabetic population for early evaluate of microvascular complications.

Conflict of interest: None. 


\section{References}

1- World Health Organization: Global report on diabetes, 2016.

2- SELVIN E. and ERLINGER T.P.: Prevalence of and risk factors for peripheral arterial disease in the United States: Results from the National Health and Nutrition Examination Survey, 1999-2000. Circulation, 110 (6): pp. 738-43, 2004.

3- McDERMOTT M.M.: The magnitude of the problem of peripheral arterial disease: Epidemiology and clinical significance. Cleveland Clinic Journal of Medicine, 73: pp. S2-7, 2006.

4- KIM E.S., WATTANAKIT K. and GORNIK H.L.: Using the ankle-brachial index to diagnose peripheral artery disease and assess cardiovascular risk. Cleve Clin. J. Med., 79 (9): pp. 651-61, 2012.

5- TEHAN P.E., BRAY A. and CHUTER V.H.: Non-invasive vascular assessment in the foot with diabetes: Sensitivity and specificity of the ankle brachial index, toe brachial index and continuous wave Doppler for detecting peripheral arterial disease. Journal of Diabetes and its Complications, 30 (1): pp. 155-60, 2016.

6- REGENSTEINER J.G., HIATT W.R., COLL J.R., CRIQUI M.H., TREAT-JACOBSON D., McDERMOTT M.M. and HIRSCH A.T.: The impact of peripheral arterial disease on health-related quality of life in the Peripheral Arterial Disease Awareness, Risk, and Treatment: New Resources for Survival (PARTNERS) Program. Vascular Medicine, 13 (1): pp. 15-24, 2008.

7- WU W.C., MOHLER E., RATCLIFFE S.J., WEHRLI F.W., DETRE J.A. and FLOYD T.F.: Skeletal muscle microvascular flow in progressive peripheral artery disease: Assessment with continuous arterial spin-labeling perfusion magnetic resonance imaging. Journal of the American College of Cardiology, 53 (25): pp. 2372-7, 2009.

8- National Institute for Health and Clinical Excellence. Type 2 diabetes in adults: Management. NICE clinical guideline, NG28, 2016.

9- American Diabetes Association: Peripheral arterial disease in people with diabetes. Diabetes care, 26 (12): pp. 333341, 2003.

10- American Academy of Ophthalmology Retina/Vitreous Panel Preferred Practice Pattern Guidelines, Diabetic Retinopathy, American Academy of Ophthalmology, San Francisco, CA. November 2016, http://www.aao.org/ppp, 2016.

11- METE T., AYDIN Y., SAKA M., CINAR YAVUZ H., BILEN S., YALCIN Y., ARLI B., BERKER D. and GULER S.: Comparison of efficiencies of michigan neuropathy screening instrument, neurothesiometer, and electromyography for diagnosis of diabetic neuropathy. International Journal of Endocrinology, 2013.

12- SHALITIN S., JOSEFSBERG Z., LILOS P., De-VRIES L., PHILLIP M. and WEINTROB N.: Bedside scoring procedure for the diagnosis of diabetic peripheral neuropathy in young patients with type 1 diabetes mellitus. Journal of Pediatric Endocrinology and Metabolism, 15 (5): pp. 613-20, 2002.
13- KWAK S.H. and PARK K.S.: Genetic studies on diabetic microvascular complications: Focusing on genome-wide association studies. Endocrinology and Metabolism, 30 (2): pp. 147-58, 2015.

14-WATTANAKIT K., FOLSOM A.R., SELVIN E., WEATHERLEY B.D., PANKOW J.S., BRANCATI F.L. and HIRSCH A.T.: Risk factors for peripheral arterial disease incidence in persons with diabetes: The Atherosclerosis Risk in Communities (ARIC) Study. Atherosclerosis, 180 (2): pp. 389-97, 2005.

15- HOOI J.D., KESTER A.D., STOFFERS H.E., OVERDIJK M.M., VAN REE J.W. and KNOTTNERUS J.A.: Incidence of and risk factors for asymptomatic peripheral arterial occlusive disease: A longitudinal study. American Journal of Epidemiology, 153 (7): pp. 666-72, 2001.

16- DIEHM C., SCHUSTER A., ALLENBERG J.R., DARIUS H., HABERL R., LANGE S., PITTROW D., VON STRITZKY B., TEPOHL G. and TRAMPISCH H.J.: High prevalence of peripheral arterial disease and co-morbidity in 6880 primary care patients: Cross-sectional study. Atherosclerosis, 172 (1): pp. 95-105, 2004.

17- WEBBER J.: Changing epidemiology of obesity-implications for diabetes. Obesity and diabetes, 978 (0470): p. $1,2009$.

18-MSHELIA D.S., GARBATI M.A., NDAHI A.A., MAMZA Y.P. and MAMZA H.A.: The usefulness of total cholesterol and high density lipoprotein-cholesterol ratio in interpreting lipid profile results of Diabetes Mellitus patients. Nigerian Journal of Clinical Practice, 12 (4), 2009.

19- CASPARD H., JABBOUR S., HAMMAR N., FENICI P., SHEEHAN J.J. and KOSIBOROD M.: Recent trends in the prevalence of type 2 diabetes and the association with abdominal obesity lead to growing health disparities in the USA: An analysis of the NHANES surveys from 1999 to 2014. Diabetes, Obesity and Metabolism, 20 (3): pp. 667-71, 2018.

20- CHAHAL S., VOHRA K. and SYNGLE A.: Association of sudomotor function with peripheral artery disease in type 2 diabetes. Neurological Sciences, 38 (1), pp. 1516, 2017.

21- MARIUS R.A., ILIUTA L., GUBERNA S.M. and SINESCU C.: The role of ankle-brachial index for predicting peripheral arterial disease. Maedica, 9 (3), p. 295, 2014.

22- BUNDÓ M., MUÑOZ L., PÉREZ C., MONTERO J.J., MONTELLÀ N., TORÁN P. and PERA G.: Asymptomatic peripheral arterial disease in type 2 diabetes patients: A 10-year follow-up study of the utility of the ankle brachial index as a prognostic marker of cardiovascular disease. Annals of vascular surgery, 24 (8): pp. 985-93, 2010.

23- HUA S., LOEHR L.R., TANAKA H., HEISS G., CORESH J., SELVIN E. and MATSUSHITA K.: Ankle-brachial index and incident diabetes mellitus: The atherosclerosis risk in communities (ARIC) study. Cardiovascular diabetology, 15 (1), p. 163, 2016.

24- HOE J., KOH W.P., JIN A., SUM C.F., LIM S.C. and TAVINTHARAN S.: Predictors of decrease in anklebrachial index among patients with diabetes mellitus. Diabetic Medicine, 29 (9), pp. e304-e307, 2012.

25- HUANG K., MA Y., WANG J., SHI S., FU L., LIU J., LI L., LU H., LIANG X., LIU Y. and JIANG H.: The corre- 
lation between transcutaneous oxygen tension and microvascular complications in type 2 diabetic patients. Journal of Diabetes and its Complications, 31 (5): pp. 886-90, 2017.

26- MANN J.F., GERSTEIN H.C., POGUE J., BOSCH J. and YUSUF S.: Renal insufficiency as a predictor of cardiovascular outcomes and the impact of ramipril: The HOPE randomized trial. Annals of internal medicine, 134 (8): pp. 629-36, 2001.

27- SOYOYE D.O., IKEM R.T., KOLAWOLE B.A., OLUWADIYA K.S., BOLARINWA R.A. and ADEBAYO O.J.: Prevalence and correlates of peripheral arterial disease in Nigerians with type 2 diabetes. Advances in medicine, 2016.

28- LIBBY P., BONOW R.O., MANN D.L. and ZIPES D.P.: Braunwald's Heart Disease: A Textbook of Cardiovascular Medicine, 2-Volume Set. Elsevier Health Sciences, 2007.

29- LEE M.Y., HSIAO P.J., HUANG J.C., HSU W.H., CHEN S.C., CHANG J.M. and SHIN S.J.: Abnormally Low or High Ankle-Brachial Index Is Associated With the Development of Diabetic Retinopathy in Type 2 Diabetes Mellitus. Scientific reports, 8 (1), p. 441, 2018.

30- CHEN S.C., HSIAO P.J., HUANG J.C., LIN K.D., HSU W.H., LEE Y.L., LEE M.Y., CHANG J.M. and SHIN S.J.: Abnormally low or high ankle-brachial index is associated with proliferative diabetic retinopathy in type 2 diabetic mellitus patients. PloS one, 10 (7): p. e0134718, 2015.

31- KLEIN R., MARINO E.K., KULLER L.H., POLAK J.F., TRACY R.P., GOTTDIENER J.S., BURKE G.L., HUBBARD L.D. and BOINEAU R.: The relation of atherosclerotic cardiovascular disease to retinopathy in people with diabetes in the Cardiovascular Health Study. British Journal of Ophthalmology, 86 (1): pp. 84-90, 2002.

32- BROWNLEE M.: The pathobiology of diabetic complications: A unifying mechanism. Diabetes, 54 (6), pp. 1615-25, 2005.

33- FAHMY E.M., EL MAHDI A.M., GABER M.A. and SAEED M.A.M.: Does brain natriuretic peptide have a significant diagnostic value in subclinical peripheral atrial disease type 2 diabetic patients? The Egyptian Journal of Internal Medicine, 29 (4), p. 189, 2017.

34- MAKHDOOMI K., MOHAMMADI A., AGHASI M.R., ZAMANI N. and VOSSUGHIAN S.: Correlation between ankle-brachial index and microalbuminuria in type 2 diabetes mellitus. Iranian Journal of Kidney Diseases, 7 (3): pp. 204-9, 2013.

35- ADLER A.I., STEVENS R.J., MANLEY S.E., BILOUS R.W., CULL C.A., HOLMAN R.R. and UKPDS Group: Development and progression of nephropathy in type 2 diabetes: The United Kingdom Prospective Diabetes Study (UKPDS 64). Kidney international, 63 (1): pp. 225-32, 2003.

36- CARDOSO C.R., MELO J.V., SALLES G.C., LEITE N.C. and SALLES G.F.: Prognostic impact of the anklebrachial index on the development of micro-and macrovascular complications in individuals with type 2 diabetes: The Rio De Janeiro Type 2 Diabetes Cohort Study. Diabetologia, 61 (11): pp. 2266-76, 2018.

37- American Diabetes Association: 11. Microvascular complications and foot care: Standards of Medical Care in Diabetes-2019. Diabetes care, 42 (Supplement 1), pp. S124-S138, 2019. 


\section{مؤثر الكاحل العضدى كلاللة للمضاعفات الآوعية الدموية الدقيقة

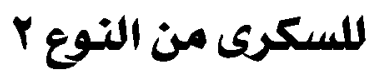

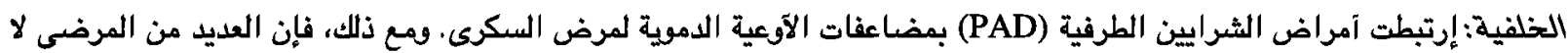

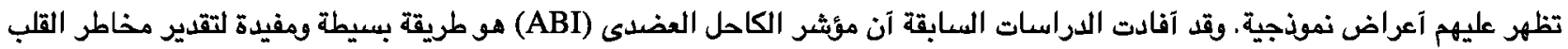
والآوعية الدموية في هؤلاء المرضى.

الهدف:تصديد ما إذا كان مؤشر الكاحل العضدى (ABI) يمكن آن يكون آداة مفيدة لتقدير المضاعفات الوعائية الدقيقة فى داء السكرى من النوع الثانى.

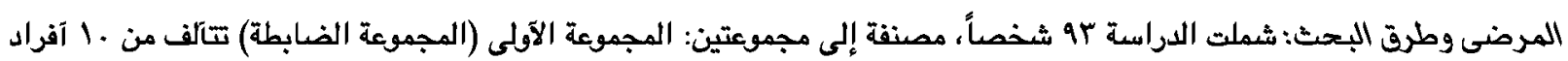

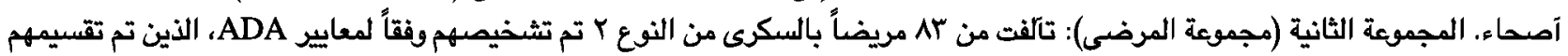

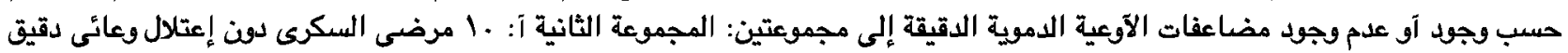

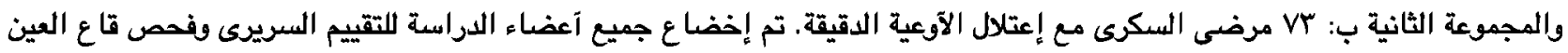

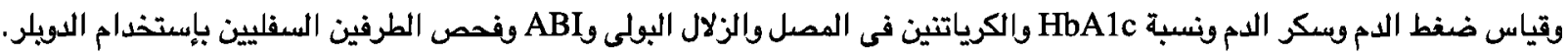

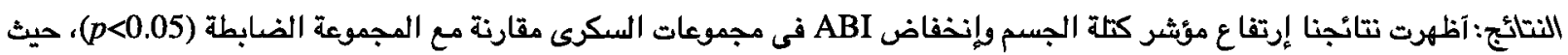

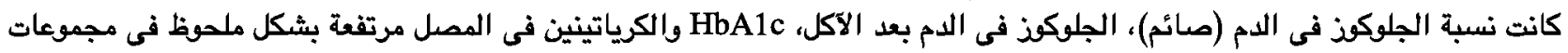

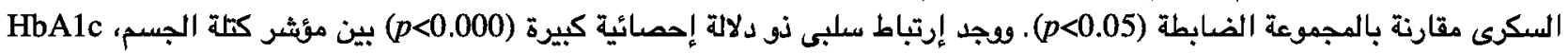

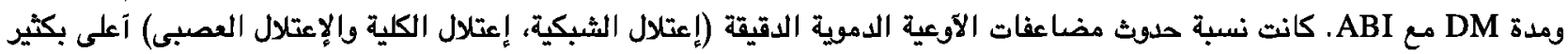

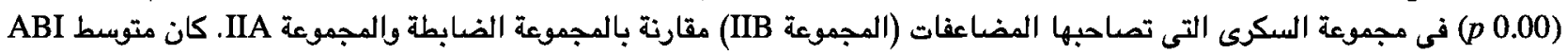

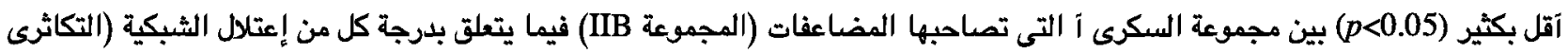
وغير التكاثرى)، إعتلال الكية والإعتلال العصبى (قليل، معتدل وشديد).

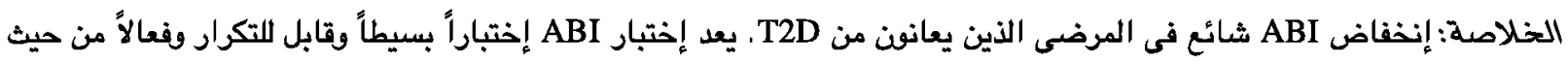

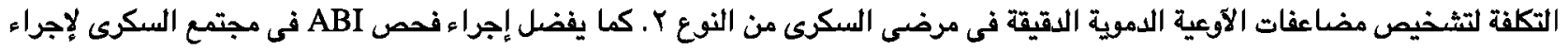
تقييم مبكر لمضاعفات الأوعية الدموية الدقيقة. 